\title{
Moeda, instabilidade financeira e hierarquia no sistema internacional
}

Currency, Financial Instability and Hierarchy in International System

Alba Bruna B. Boaventura ${ }^{1}$

\section{RESUMO}

Este artigo analisa o papel da moeda na instabilidade financeira e na hierarquização dos países no sistema internacional pós-Bretton Woods e como os conflitos monetários se aprofundam após a crise de 2008. Nesse sentido, indica-se como a financeirização da economia e a guerra monetária interferem na gestão das políticas monetárias domésticas e restringem as possibilidades de desenvolvimento, sobretudo as dos países periféricos.

Palavras-chave: moeda; financeirização; hierarquia internacional.

\begin{abstract}
This paper analyzes the currency's role in financial instability and hierarchization of countries in the international system post-Bretton Woods and how the monetary conflicts deepen after the 2008 crisis. In this sense, it is indicated how the financialization of the economy and the currency war interfere in the management of domestic currency policies and restrict the possibilities of development, especially those of peripheral countries.
\end{abstract}

Key-words: currency, financialization, international hierarchy.

\section{INTRODUÇÃO}

O sistema monetário e financeiro internacional sofreu mudanças significativas em sua dinâmica desde o final do sistema de Bretton Woods. Entretanto, ao longo do período, há uma constante: a persistência da hierarquização dos Estados no sistema internacional em função do alcance internacional de sua moeda. Assim, o objetivo deste artigo é analisar qual o papel da moeda e do crédito na instabilidade financeira e na hierarquização dos Estados dentro do sistema internacional.

A partir da década de 1970, em virtude do fim da regulamentação imposta por Bretton Woods, as taxas de juros e de câmbio passaram a ser reguladas pelo mercado e ${ }^{1}$ Graduanda em Relações Internacionais, Universidade Federal de Sergipe, São Cristóvão, Brasil. 
os controles dos fluxos de capitais foram abandonados. Nesse contexto de liberalização, os agentes econômicos criaram novas formas de moedas privadas, as quais proliferaram e produziram uma ruptura na visão tradicional do sistema bancário, que, não podendo mais ser apenas um intermediário financeiro internacional, passou a atuar nos mercados de títulos privados ao securitizar o crédito.

Com essa mudança nos domínios bancários, a predominância do capital fictício conheceu o seu ápice. Como se verá desenvolvido a seguir, o capital fictício é o capital que se forma e se acumula descolado da economia real. Hoje, essas atividades especulativas se tornaram a principal fonte de lucro para os agentes econômicos, o que reflete a atual financeirização da economia, que é a primazia das operações financeiras em relação às produtivas. Consequentemente, a concorrência econômica foi acirrada e, à medida que os agentes assumem mais riscos para garantir seus lucros rápidos, o risco sistêmico se amplia, haja vista a relação entre capital fictício, produtivo e as relações de crédito.

Além desse contexto de instabilidade econômica, ainda se somam as mudanças na configuração de poder, pois, com a ascensão chinesa, os debates sobre as possíveis alternativas ao dólar ganham mais notoriedade. Observa-se que as políticas ensejadas pelo Federal Reserve System (Fed) têm recebido uma série de críticas nos últimos anos, principalmente após a crise de 2008. A implicação disso na seara monetária é o conflito entre as moedas no âmbito externo. Para países periféricos, cujas moedas funcionam mal como reserva de valor ${ }^{2}$, a determinação do câmbio depende das idiossincrasias estadunidenses e das demais moedas conversíveis, que podem provocar valorizações e desvalorizações indesejadas.

Portanto, diante desse cenário de volatilidade das taxas e de mobilidade de capitais, essa discussão se justifica pelas dificuldades enfrentadas pelos países em controlar o valor de suas moedas e escolher suas políticas internas diante de crises, fatores que comprometem a autonomia e o crescimento. Mediante a guerra monetária, a instabilidade cambial dos países periféricos é um dado e suas opções estão circunscritas à esfera produtiva, que sofre pela dificuldade de ofertas de crédito.

\footnotetext{
${ }^{2}$ A moeda tem três funções: a de meio de troca, uma forma de pagamento no comércio entre os agentes econômicos; a de unidade de conta, que determina os valores referenciais na realização dos contratos; e a de reserva de valor, modo de acumular poder aquisitivo e medir riqueza, já que se trata de um ativo líquido com um poder de compra salvaguardado ao longo do tempo.
} 
Assim sendo, este artigo se divide em duas seções. Inicialmente se discutem os desdobramentos da inovação financeira pós-Bretton Woods e as mudanças observadas, sobretudo no que diz respeito à inserção dos países nesse contexto. Também são expostos meios para lidar com o risco sistêmico e com a desregulamentação na conjuntura econômica atual. Em seguida, abordam-se as possíveis alternativas ao dólar, bem como as implicações da hierarquia econômica para países periféricos, especialmente o Brasil, e conclui-se com as considerações finais.

\section{MOEDA, FINANCEIRIZAÇÃO E INSTABILIDADE}

Segundo Belluzzo (1997, p. 154), a moeda tem um caráter contraditório, pois "o dinheiro é, simultaneamente, um bem público e um instrumento de enriquecimento privado". Os agentes econômicos buscam sempre formas de produzir inovações financeiras e, dentro dessa estratégia, o papel da moeda foi revolucionado a partir da década de 1970 devido à proliferação de novas formas de moedas privadas, que as autoridades monetárias têm muita dificuldade em controlar (GUTTMANN, 1998). Tal movimento foi impulsionado pela desregulamentação de cunho neoliberal que transformou o sistema internacional ao eliminar a estrutura reguladora da moeda e o papel tradicional de intermediador do sistema bancário.

Com a liberalização, as taxas de câmbio (em 1973) e de juros (em 1979) passaram a ser reguladas pelo mercado, o que as tornou extremamente voláteis. Para se proteger dessa volatilidade, os agentes econômicos buscaram securitizar o crédito por meio da ampliação de mecanismos de transferência de riscos, como, por exemplo, os derivativos $^{3}$. No entanto, essa tendência desencadeou um aumento no capital fictício decorrente da especulação com ativos financeiros, o que afeta a economia real.

Em consequência, a visão tradicional do banco como órgão com acesso a informações privilegiadas, que permite que a acumulação do capital se liberte da poupança prévia pela criação da moeda de crédito e que, por oferecer maior segurança

\footnotetext{
3 Trata-se de contratos que derivam de outros valores, como ativos físicos ou financeiros, taxas de referência ou índices. São negociados a partir de contratos preestabelecidos e têm como principal função proteger os agentes das variações de preço. Por exemplo, um uso rotineiro de derivativos é o caso de uma empresa brasileira exportadora: ela tem receita em dólar e despesas em reais. As variações bruscas na taxa de câmbio são um problema, porque o valor da receita em reais se torna incerta, então a empresa faz um contrato de venda de dólar no futuro a uma determinada taxa para facilitar seu planejamento, mas, dependendo do comportamento do câmbio, esses contratos podem gerar perdas financeiras.
} 
que o mercado para aplicações, reduz a preferência dos poupadores pela liquidez, foi modificada. Aglietta (2004) propõe que essa mudança ocorreu em razão das inovações financeiras, e Guttmann (1998) afirma que ela foi favorecida pela revolução na informática e nas telecomunicações.

Tendo seu papel usurpado pelas novas formas de financiamento, os bancos tiveram que buscar novos domínios. A preferência por títulos como forma de captação e financiamento foi ampliada e os bancos comerciais começaram a participar desse movimento ao securitizar o crédito. Todavia, Belluzzo (1997) e Aglietta (2004) fazem considerações sobre essa tendência de distribuição dos riscos: o primeiro frisa que os derivativos repartem o risco individual, mas ampliam o sistêmico; já o último diz que os derivativos criam risco de liquidez e de crédito nos mercados secundários em que são negociados e, sendo assim, mesmo que eles não criem os riscos globais, os propagam em contextos de instabilidade macroeconômica.

Devido ao envolvimento dos bancos comerciais nos mercados de títulos, o capital fictício se proliferou. 0 capital fictício é uma categoria de circulação cujo valor não tem relação direta com a produção, que depende de uma renda futura que lhe sirva de base para que haja a capitalização de seu valor através de uma taxa de juros. Guttmann, ao citar Marx (1894), afirma que as fontes principais de capital fictício são "os fundos próprios (ações) cotados na bolsa, os títulos da dívida pública e a moeda de crédito propriamente dita" (GUTTMANN, 1998, p. 77). Dessa forma, a participação dos bancos nesse mercado permitiu a alavancagem e estimulou o aumento dos derivativos.

Farhi (1999), Mollo (2011) e Guttmann (1998) analisam como a grande flexibilidade dos derivativos transformou a especulação - isto é, a capacidade de se "antecipar em condições nas quais as variáveis que participam na formação do preço são incertas" (AGLIETTA, 2004, p. 45) - ao torná-la uma grande fonte de rendimento para empresas, instituições financeiras e poupadores individuais. Atualmente ela representa o tipo de investimento básico do capital fictício e foi bastante propagada pela liberalização dos movimentos de capital.

A atração exercida pelas atividades especulativas e outras formas de capital fictício consiste na capacidade que elas têm de prosperar relativamente isoladas do resto da economia, haja vista que tais instrumentos têm uma autonomia relativa. Entretanto, pelo capital fictício ter atualmente várias formas de operações creditícias e 
de transações com títulos, suas repercussões não estão circunscritas apenas ao setor financeiro, de modo que as crises também podem ser transmitidas tanto para a esfera produtiva como para a esfera creditícia.

No caso da crise de 20084, Mollo (2011) elucida como a liberalização e os respectivos processos de desregulamentação estimularam a especulação em desfavor da produção e como isso estaria no cerne da crise. Essa dinâmica reflete a financeirização da economia, ou seja, o predomínio das operações financeiras sobre as produtivas. A autora afirma que a autonomia relativa entre circulação e produção está associada ao processo de geração de rendas - lucros e salários provenientes da produção - que sustentam as compras dos ativos. Se a renda não cresce ou cresce pouco e, por conseguinte, não fornece a demanda necessária à manutenção da valorização fictícia do capital, a demanda e os preços dos títulos caem, o que mostra o caráter fictício.

Segundo Brunhoff (2010), a expansão da concorrência econômica e financeira também aumentou a pressão sobre os assalariados pela insegurança em relação aos empregos. A finança contribui para a internacionalização do mercado capitalista e, com isso, ela enfraquece a solidariedade de classe e favorece a concorrência entre financistas, entre os Estados e entre os trabalhadores. Ainda que as perdas nesse mercado não tenham relação direta com a produção, com a economia real, elas interrompem os investimentos e ampliam o desemprego (MOLLO, 2011). Além disso, para compensar as altas taxas de juros, há uma tendência à redução de custos através da contenção dos salários. A concorrência acirrada favorece ainda o progresso tecnológico e, se a produção real não se ampliar, absorver a demanda de trabalho se torna mais difícil. Os trabalhadores, portanto, sofrem com os custos sociais desse processo.

O perigo do capital fictício posto por Guttmann (1998) se encontra exatamente aí: os operadores tendem a reagir de forma exagerada nessas situações, na medida em que todos, simultaneamente, buscam segurança, o que pode destruir o capital fictício pela deflação maciça dos ativos. Como uma reação em cadeia, os prejuízos podem se

\footnotetext{
${ }^{4}$ A crise de 2008, também conhecida como a crise do subprime, foi ocasionada pelo excesso de hipotecas realizadas para clientes de alto risco pelos bancos. Para reduzir o risco, esses bancos emitiam títulos de dívida lastreados nas hipotecas, ou seja, securitizavam as hipotecas. Com o aumento dos juros, os devedores deixaram de pagar as hipotecas e o sistema começou a desmoronar. Com a falência do Lehman Brothers, quarto maior banco de crédito estadunidense, iniciou-se um pandemônio financeiro e foi apenas com a injeção de liquidez dos EUA que o mercado pôde ser apaziguado.
} 
estender para a esfera industrial pelas quedas de demanda parcialmente destinadas à produção real, bem como para o capital de empréstimo pelas restrições creditícias.

Buscando reduzir os efeitos das flutuações e impedir a saída de grandes volumes de capitais, as altas taxas de juros se tornaram o novo mecanismo regulador dos fluxos de capitais e tentam reduzir os riscos que a volatilidade traz para as políticas internas. Porém, observa-se que essa tendência, na verdade, constrange as escolhas de políticas internas dos países, especialmente dos periféricos, uma vez que as movimentações na taxa de juros dependem dos mercados externos, e o crescimento e o emprego são restringidos. Sob essa ótica, são notórias as discrepâncias monetárias e financeiras existentes entre países centrais e países periféricos.

Conforme apontado por Belluzzo (1997, p. 187), “a inserção dos países nesse processo de globalização foi hierarquizada e assimétrica". Segundo Brunhoff (2010), no atual sistema monetário, a hegemonia do dólar está apoiada no poder econômico estadunidense. 0 dólar funciona como o padrão monetário, as taxas de juros geradas pelo banco central dos EUA têm força - embora a autora ressalve que há limitações - e existe um consenso político que reconhece essas dinâmicas.

Carneiro (2008), por sua vez, salienta como a moeda reserva, por ser a representação abstrata da riqueza, pode definir as taxas de juros básicas do sistema de modo unilateral. Além disso, ele ressalta como a questão da inconversibilidade, ou seja, a falta de aceitação da moeda no âmbito internacional, ganhou mais importância pela crescente mobilidade de capitais. As moedas são hierarquizadas no sistema monetário internacional pelo seu tamanho ou peso nesse sistema, bem como pelo seu pecado original $^{5}$. Elas sofrem riscos de crédito e riscos de preços, variáveis que dependem da moeda reserva: o dólar.

Por outro lado, os países desenvolvidos são imunes a esse risco de crédito, pois “o poder soberano desses Estados torna seus títulos emitidos e financiados em moeda nacional perfeitamente solvíveis" (AGLIETTA, 2004, p. 51). 0 poder, portanto, implicaria solvibilidade. Ademais, o autor também destaca a importância de uma estrutura de financiamento eficaz, de modo a estimular o investimento produtivo. Desde o início, é importante existir uma estrutura de financiamento que aposte na qualidade de um

5 Termo de Eichengreen, Hausmann e Paniza (2003) citado por Carneiro que diz respeito à impossibilidade de um país se endividar na sua própria moeda. 
projeto de investimento, isto é, que forneça crédito para a sua execução. Diante da financeirização da riqueza, os bancos perdem a capacidade de fornecer crédito à economia, o que, segundo Aglietta (2004), explicaria, por exemplo, o marasmo econômico japonês durante os anos 1990.

Mollo (2011) afirma que essa hierarquia ocorre pela existência de moedas que funcionam mal como reserva de valor em escala mundial. Dessa forma, os países periféricos e menos desenvolvidos apresentariam alto risco e por essa razão estariam mais sujeitos a movimentos de fuga de capitais em situações de incerteza. As flutuações ao longo dos ciclos de liquidez dos mercados abalam e moldam o crescimento gerado por esse fluxo. Em decorrência desses fatores, a independência das políticas monetárias é comprometida.

Na verdade, conforme posto por Belluzzo (1997), houve renúncia de soberania na conduta das políticas econômicas. Ao buscar garantir a hegemonia do dólar pósBretton Woods nas transações internacionais, os Estados Unidos ensejaram um sistema de paridades cambiais instável e problemático, e o papel de seigniorage exercido por esse país foi aceito pelo sistema, ao menos por ora. 0 raio de manobra das políticas monetárias está sendo constrangido, sobretudo pelo que acontece no mercado financeiro internacional, cujo epicentro está nos Estados Unidos e tem como padrão monetário o dólar.

Entretanto, no atual sistema internacional, os bancos centrais têm dificuldades para defender suas moedas contra ataques especulativos apenas com o aumento das taxas de juros. As discussões sobre o risco sistêmico suscitam alguns questionamentos sobre o papel do banco central em oferecer "uma garantia coletiva contra o risco sistêmico justamente onde as seguradoras privadas são impotentes" (AGLIETTA, 2004, p. 56). De acordo com Aglietta (2004, p. 46),

os problemas de coordenação que conduzem ao risco sistêmico são disfunções nos sistemas financeiros que agravam as assimetrias de informações e contêm externalidades que suscitam a fragilidade financeira por antisseleção (seleção de maus tomadores) e risco moral (incitação dos tomadores a assumirem mais riscos).

Então, através da liberalização financeira, o risco sistêmico seria aumentado pelo endurecimento da concorrência, pois amplia a disposição dos agentes a assumir 
riscos, o que pode deteriorar a alocação eficiente de recursos, elevando a possibilidade de despontarem crises financeiras. A desregulamentação acirra a concorrência pela necessidade de lucros rápidos, que, conforme apontado por Mollo (2011), são muito mais fáceis de conseguir em operações especulativas do que nos investimentos produtivos.

A solução para repelir o risco sistêmico, segundo Aglietta (2004), seria intervir nos processos que conduzem à crise. A regulamentação preventiva proposta por esse autor se concentra em regulamentar e supervisionar a tomada de precauções contra os comportamentos geradores de riscos, reduzir a assimetria de informação e evitar a propagação dos acidentes financeiros locais. 0 emprestador em última instância, isto é, o banco central, entra em ação quando o dispositivo preventivo não funciona, o que traz para o debate a questão sobre as características e a forma de atuação do banco central.

Blinder (1999) afirma que o banco deveria ter independência de instrumento, mas não de objetivo. As análises e avaliações do banco central sobre as políticas monetárias poderiam se tornar mais transparentes e ele deveria ter independência em relação aos mercados financeiros e à política, bem como credibilidade, pois assim as campanhas deflacionárias seriam efetivas para diminuir a inflação real sem o custo de desemprego. Aglietta (2004) entende que a injeção de liquidez dos bancos centrais em situação de crise é necessária, especialmente após a liberalização, mas acredita que é preciso ficar atento ao risco moral, gerado pela probabilidade de os maus tomadores de empréstimos assumirem cada vez mais riscos e acabarem por não ter condições de cumprir suas obrigações.

Por sua vez, Belluzzo (1997) afirma que, devido aos riscos morais trazidos pelas intervenções de última instância dos países centrais para conter crises sistêmicas, atualmente as autoridades precisam fazer aterrissagens suaves ${ }^{6}$, o que não tem desestimulado as tendências especulativas no mercado e ainda agrava o viés altista que amplifica os problemas de sobrevalorização nos mercados de ativos. Guttmann (1998), em contrapartida, ressalva como a ação prestamista potencializa o problema das condutas irresponsáveis, já que os agentes financeiros irresponsáveis esperam esse socorro em última instância.

\footnotetext{
${ }^{6}$ Política econômica que tenta controlar a taxa de crescimento e evitar as bolhas de especulação financeira, de modo que o crescimento se mantenha alto o suficiente para impedir a recessão, mas não provoque inflação no nível dos preços e dos ativos financeiros.
} 
No entanto, o alto nível de volatilidades de capitais impede que o sistema monetário e financeiro internacional contemple os três requisitos identificados por Eichengreen (1995) como necessários para a estabilidade desse sistema: capacidade de ajustar os preços relativos, adesão de todos os participantes a regras monetárias robustas e habilidade para conter pressões de mercado. Pela estruturação crescente dos mercados de trabalho, politização das políticas econômicas e ampliação dos desafios para conter pressões do mercado, há dificuldade em satisfazer os pré-requisitos para a estabilidade monetária internacional. Na mesma lógica da credibilidade, o autor está de acordo com Blinder (1999), que afirma que, se o governo tivesse a reputação de defensor da paridade cambial, os operadores de câmbio apostariam na sustentação dessa paridade sempre que ela se enfraquecesse. Entretanto, o volume de capitais movimentados pelos agentes financeiros supera os recursos disponíveis para os bancos centrais fazerem política monetária, dificultando, portanto, a estabilização e a conquista da credibilidade.

Uma alternativa para enfrentar os problemas gerados pela desregulamentação seria a coordenação internacional. Aglietta (2004) acredita que a autoridade do Fundo Monetário Internacional (FMI) poderia ser reforçada pela reforma no plano externo, redistribuindo os direitos de votação e reestruturando o aparato administrativo, e no plano interno, ao instalar um verdadeiro executivo político. Para Eichengreen (1995), deve-se aprender a conviver com as taxas de câmbio flutuantes, e os meios para tanto seriam: criação de moeda única, de câmaras de conversão ${ }^{7}$, de bandas cambiais $^{8}$ e do imposto Tobin'. Guttmann (1998) defende que seria necessária uma reforma na direção de uma moeda de crédito supranacional, que fosse emitida e administrada por uma autoridade monetária internacional. Assim, supõem-se uma racionalidade e uma capacidade de coordenação dos agentes políticos que os autores não esperam encontrar nos agentes econômicos. Eles reconhecem a natureza concorrencial da economia mundial, mas tendem a enfatizar os aspectos cooperativos da política internacional e sua capacidade de regular a economia.

\footnotetext{
${ }^{7}$ Regime que só emite moeda nacional quando há uma contrapartida na moeda reserva do sistema a uma taxa fixa.

${ }^{8}$ Regime em que as autoridades monetárias delimitam o intervalo em que a taxa de câmbio pode flutuar. Quando há variações fora do valor mínimo ou máximo, os bancos centrais intervêm para normalizar a taxa, comprando ou vendendo moeda estrangeira.

${ }^{9}$ Imposto Tobin é um tributo sugerido por James Tobin, economista estadunidense, que busca impor uma taxa de $0,1 \%$ nas transações financeiras entre os países, a fim de reduzir a especulação.
} 
A grande questão atual é que, com o mercado financeiro sobrepujando os demais, o crescimento de toda a economia tem sido afetado. Conforme posto por Belluzzo (1997), o crescimento das finanças ocorre em detrimento dos outros setores, como o industrial e o de infraestrutura. Portanto, reformar os mecanismos de regulação se tornou imperativo, mas nenhuma das saídas apontadas por Aglietta, Eichengreen ou Guttmann mostra-se viável. O próprio Guttmann (1998, p. 96) afirma que "será necessária uma pressão muito forte para que os condutores das políticas econômicas sejam forçados à ação coordenada em direção a um novo regime monetário".

\section{HIERARQUIA INTERNACIONAL E GUERRA MONETÁRIA}

A conjuntura contemporânea, no que toca à configuração de poder, ainda passa por mudanças significativas que podem ter implicações na hierarquia econômica, pois "à medida que a economia mundial se torna multipolar, seu sistema monetário, sugere a lógica, deve, da mesma maneira, seguir a tendência, também se tornando multipolar" (EICHENGREEN, 2011, p. 119). De acordo com Eichengreen (2011, 2013), os EUA têm ensejado políticas deflacionárias com impactos negativos em economias periféricas, além de demonstrar disfunções nos seus mercados financeiros desde a crise de 2008. Dessa forma, o debate que há muito tempo especula qual seria a moeda alternativa ao dólar ganha mais força, principalmente pela possível alteração na hierarquia monetária devido à ascensão chinesa.

Diante dessa hipótese, Eichengreen (2011) discute as principais alternativas ao dólar: o euro, os direitos especiais de saque (SDRs) e o renminbi. Para o autor, apesar de a moeda oficial de 19 dos 28 países da União Europeia (UE) ter apenas dez anos e sua região não ser detentora do maior ou mais líquido mercado de títulos de dívida, o euro segue sendo um refúgio seguro para governos e investidores, com uma grande área capaz de oferecer os necessários instrumentos de dívida, um grande mercado de bônus e um banco central que atue na estabilidade de preços e seja emprestador em última instância. 0 problema do euro é que ele é uma moeda sem Estado, que depende da convergência de interesses nacionais para sua coordenação.

Além disso, a capacidade de crescimento da UE está em xeque, tanto pela estagnação demográfica que pode levar à estagnação econômica quanto pelo seu mercado de trabalho inflexível, que apresenta dificuldades na contratação e manutenção 
de mão de obra. Tais fatores diminuem a atração do euro enquanto moeda reserva, mas isso não significa que essa situação não possa ser modificada no futuro próximo. Por essa razão, o autor defende que seja necessária mais vontade política europeia para completar a integração, de modo que haja maior supervisão e maior coordenação de políticas fiscais e mecanismos financeiros de pronto atendimento, a fim de possibilitar a agilidade das decisões em cenários de crise e que, assim, a moeda possa se tornar uma alternativa viável ao dólar.

Os SDRs, por seu turno, têm ainda mais problemas que o euro. 0 autor afirma que essa unidade monetária possui serventia apenar para liquidar dívidas com governos ou com o FMI, não podendo ser utilizado para intervir em mercados privados, faturar ou liquidar transações comerciais, ou conseguir empréstimos e financiamentos privados. Para que eles fossem usados nessas transações, algum país deveria assumir o ônus da iniciativa, e a experiência fracassada de criar um mercado privado de SDRs na década de 1980 não estimula novas tentativas.

Outro fator que diminui a atração dessa unidade é a dificuldade na decisão sobre a emissão, dado que quaisquer acréscimos dependem da decisão dos países que têm $85 \%$ dos direitos de voto no FMI. Como no caso do euro, as decisões dos SDRs são coordenadas e mesmo sua conversão nas moedas reservas demora no mínimo cinco dias, o que, como afirmado por Eichengreen (2011), é uma eternidade em uma crise. Para que esse cenário fosse modificado, seriam necessárias maior autonomia e ampliação do papel do FMI no cenário internacional, de modo que ele funcionasse como um banco central global ao fornecer a liquidez emergencial necessária à economia. Todavia, o autor é categórico: enquanto não houver governo global, não haverá banco central ou moeda global, sendo, portanto, impraticável atribuir ao FMI essa posição.

O renminbi, no entanto, é uma alternativa lógica, visto que a China é a segunda maior economia mundial, que apresenta um contínuo crescimento e tem como objetivo tornar Xangai o centro financeiro internacional até 2020. Segundo Eichengreen (2011), como primeiro passo da internacionalização monetária, o uso do renminbi tem sido encorajado nas transações comerciais regionais em algumas empresas selecionadas, além de alguns acordos bilaterais extrarregionais terem sido firmados, como o do Brasil, para estimular o uso da moeda de ambos os países em transações comerciais. Abriramse também contas de depósito nessa unidade monetária em Hong Kong, que depois 
estendeu esse benefício para qualquer empresa do mundo, criando um mercado interbancário sediado nessa unidade administrativa.

Como segundo passo, a partir de 2009, com o HSBC Holdings, o país também permitiu que outras transações financeiras no exterior fossem realizadas pelos investidores estrangeiros em renminbi. O Banco Popular Chinês se movimenta com cautela para a emissão de onshore por bancos e empresas estrangeiras e organismos multilaterais em Xangai, já que isso aumentaria a aceitação do renminbi pelos exportadores. Eichengreen (2011) defende que a participação nas reservas internacionais tem sido incentivada pela Chiang Mai Initiative Multilateralization e pelos acordos de swaps, que começaram com a Coreia do Sul em dezembro de 2008 e se estenderam para Argentina, Belarus, Hong Kong, Indonésia, Malásia, Paquistão e Rússia. Portanto, nota-se que a China está comprometida com a internacionalização de sua moeda, mas, para alcançar esse intento, Eichengreen (2011) frisa que ela deve abrir totalmente seus mercados financeiros aos investidores, mudar seu modelo de desenvolvimento e converter sua conta de capital, condutas que devem ser retardadas pela recente instabilidade financeira chinesa.

Mas "nada disso significa que o dólar perderá o status de moeda internacional, apenas que terá rivais" (EICHENGREEN, 2011, p. 149). Como apontado pelo autor, o status quo do dólar é autorreforçador, já que os investidores estrangeiros buscam o mercado estadunidense por se tratar do maior e do mais líquido, e essa busca, por conseguinte, aumenta a liquidez desse mercado. Os títulos de dívida, os derivativos, a maior parte dos papéis lançados no mercado internacional por agentes econômicos privados são denominados em dólar. Então, o papel do dólar como moeda reserva do sistema internacional "cria uma grande demanda de possuir dólares como reservas de riqueza - o 'privilégio exorbitante' de que Charles de Gaulle se queixou há duas gerações" (COHEN; DELONG, 2012, p. 71). As vantagens dessa posição são assinaladas por Eichengreen $(2011,2013)$ e Cohen e Delong (2012), que demonstram como o endividamento estadunidense está vinculado à lógica do crescimento econômico mundial, o que estimula déficits orçamentários gigantescos, com táticas como a inflação para atenuar o ônus da dívida.

Em 2010, as políticas não convencionais do Fed receberam críticas brasileiras e de alguns outros países por se assimilarem às políticas dos anos 1930, cujo objetivo era 
estimular a competitividade de um país e diminuir a do outro. Eichengreen (2013) explica que tais políticas para afastar a deflação e estimular a economia desencadearam uma migração dos fluxos de capitais para países emergentes, acarretando valorização da moeda e dos ativos, fator que repercutiu na competitividade, além de provocar inflação. 0 termo cunhado pelos emergentes foi guerra cambial, já que quaisquer mudanças ascendentes ou decrescentes no valor do dólar tinham impactos nas moedas estrangeiras por conta do atrelamento. Como ironizado por John Connally - secretário do Tesouro de Nixon -, citado por Cohen e Delong (2012, p. 72), a instabilidade é do dólar, mas o problema é do mundo inteiro.

No cenário atual, no qual as finanças têm primazia em relação às atividades produtivas e os capitais têm cada vez mais mobilidade, as consequências das posições ocupadas pelas moedas periféricas, como é o caso do real brasileiro, tornam-se ainda mais evidentes. A hierarquia monetária é formada pelas moedas que recebem o status de conversíveis ou inconversíveis, sendo as últimas aquelas unidades que funcionam mal como reserva de valor, incapazes de emitir dívida e de estabelecer relações financeiras de longo prazo. Além desse fator estrutural, a dinâmica observada entre elas é concorrencial e, assim, o valor do real fica à mercê das vicissitudes monetárias internacionais. A guerra monetária supracitada implica um aumento da dificuldade de países periféricos como o Brasil determinarem o valor de sua própria moeda. Diante da desvalorização do dólar, a UE, a China e o Japão possuem a capacidade de desvalorizar suas moedas para compensar, o que acaba forçando a valorização das moedas dos países mais vulneráveis do sistema. Para além das consequências, assinaladas por Carneiro (2008), do mau funcionamento da moeda enquanto reserva de valor, como a acumulação de capital circunscrita à seara produtiva e o bloqueio de processos de concentração na esfera financeira, países periféricos ainda sofrem pela dificuldade de introduzir o controle cambial, variável crucial para políticas de estabilização do balanço de pagamentos num contexto de instabilidade financeira.

\section{CONSIDERAÇÕES FINAIS}

A crescente mobilidade de capitais e a volatilidade das taxas de juros e de câmbio num contexto de financeirização econômica têm repercutido no crescimento da economia mundial, apesar de severas recessões e deflações terem sido evitadas. Os 
reflexos negativos do capital fictício e seus desdobramentos nos demais tipos de capital já são sentidos desde a crise de 2008, e o questionamento sobre quais medidas ortodoxas ou heterodoxas - devem ser adotadas para estimular a economia permanece sem resposta.

Contudo, se países centrais sofrem para contornar crises financeiras e achar políticas que possam atenuá-las, a situação dos países periféricos é ainda mais delicada, visto que eles sofrem tanto pelo fator conjuntural como pela sua própria dinâmica interna. A escolha de políticas para lidar com as crises perpassa por uma série de restrições em função do alcance internacional de suas moedas. Quaisquer movimentações nas taxas de juros ou no câmbio do dólar e a consequente compensação das demais moedas resultam em mudanças em suas taxas, que são completamente vulneráveis nesse processo. Isso gera empecilhos na implantação de políticas que contemplem ajustes nos balanços de pagamentos durante crises financeiras.

Como supracitado, uma vez que países periféricos não obtêm financiamento de longo prazo, os investimentos na esfera produtiva são dificultados. Por seus mercados financeiros serem de alto risco, eles são incapazes de emitir dívida, o que bloqueia seus recursos nesse mercado. 0 crescimento e a renda são restringidos e eles se tornam completamente dependentes de outras formas para prosperar, como a entrada de investimento estrangeiro direto. Desse modo, o mau funcionamento de suas moedas e suas posições na hierarquia internacional impõem barreiras para o desenvolvimento dos países periféricos.

Logo, conforme foi apresentado, o processo de liberalização financeira desencadeado pelo final do acordo de Bretton Woods induziu o surgimento de inovações financeiras e a financeirização da riqueza. Esses processos agravaram a desigualdade monetária internacional, aumentaram os fatores de instabilidade e crise e reduziram a capacidade dos Estados periféricos de fazer política monetária independente da dinâmica dos fluxos internacionais de capitais.

Ademais, as dinâmicas de poder são vinculadas às lógicas monetárias. Reformar os mecanismos de regulação é imperativo, mas não se pode considerar o FMI como o protagonista nesse processo por se tratar de uma instituição que reforça o status quo, sendo, portanto, difícil sequer imaginar mudanças na distribuição de poder que contrariem os privilégios das grandes potências. Na verdade, devido à proliferação de 
moedas privadas e à magnitude dos lucros alcançados na especulação, impor um novo marco regulatório parece improvável e impraticável. Os agentes econômicos e políticos só considerarão coordenar ações para driblar a desregulamentação - como, por exemplo, outra inovação financeira - se eles pararem de ser beneficiados por esse processo através dos lucros exorbitantes. Assim, resta saber se a configuração da economia contemporânea ainda comporta crescimento nos próximos anos ou se esta década também está fadada a ser perdida.

\section{REFERÊNCIAS BIBLIOGRÁFICAS}

AGLIETTA, Michel. Macroeconomia financeira, vol.1: mercado financeiro, crescimento e ciclos. São Paulo, Loyola, 2004.

AGLIETTA, Michel. Macroeconomia financeira, vol.2: crises financeiras e regulação monetária. São Paulo, Loyola, 2004.

BELLUZZO, Luiz Gonzaga. Dinheiro e as transformações da riqueza. In: TAVARES, Maria da Conceição e FIORI, José Luiz (orgs.). Poder e dinheiro: uma economia política da globalização. Petrópolis, Vozes, 1997.

BLINDER, Alan S. Bancos Centrais: teoria e prática. São Paulo, Editora 34, 1999.

BRUNHOFF, Suzanne de. Finança, capital, Estados. In: BRUNHOFF, Suzanne de et alli. A finança capitalista, São Paulo, Alameda, 2010.

CARNEIRO, R. M. Globalização e inconversibilidade monetária. Revista de Economia Política, v. 28, p.539-556, 2008. Disponível em: <www.eco.unicamp.br/docprod/downarq.php?id=1750\&tp=a>. Acesso em: 02/04/2016.

DELONG, J. Bradford. O Fim da Influência: como fica o mundo quando o dinheiro muda de mãos. São Paulo, Évora, 2012.

EICHENGREEN, Barry. História e reforma do sistema monetário internacional. Economia e Sociedade, Campinas, vol. 4, n. 1, 1995. Disponível em: <www.eco.unicamp.br/docprod/downarq.php?id=424\&tp=a>. Acesso em: 02/04/2016.

EICHENGREEN, Barry. The renminbi as an international currency. Journal of Policy Modeling, vol.33, n.5, pp.723-730, 2011. Disponível em: <http://eml.berkeley.edu/ eichengr/renminbi_international_1-2011.pdf>. Acesso em: 02/04/2016.

EICHENGREEN, Barry. Privilégio Exorbitante: a ascensão e queda do dólar e o futuro do Sistema Monetário Internacional. Rio de Janeiro, Elsevier, 2011.

EICHENGREEN, Barry. Currency war or international policy coordination. Journal of 
Policy Modeling, vol.35, n.3, pp.425-433, 2013. Disponível em: <http://eml.berkeley.edu/ eichengr/curr_war_JPM_2013.pdf>. Acesso em: 02/04/2016.

FARHI, Maryse. Derivativos Financeiros: Hedge, Especulação e Arbitragem. Economia e Sociedade, Campinas - SP, v. 13, p. 93-114, 1999. Disponível em: <http://www3.eco.unicamp.br/cecon/images/arquivos/publicacoes/publicacoes_23_3 961167024.pdf>. Acesso em: 02/04/2016.

GUTTMANN, Robert. As mutações do capital financeiro. In: CHESNAIS, François (coord.). A mundialização financeira: gênese, custos e riscos. São Paulo, Xamã, 1998.

MOLLO, Maria de Lourdes Rollemberg. Crédito, capital fictício, fragilidade financeira e crises: discussões teóricas, origens e formas de enfrentamento da crise atual. Economia e Sociedade, Campinas, v. 20, n. 3 (43), p. 449-474, dez. 2011. Disponível em: <http://www.scielo.br/pdf/ecos/v20n3/a01v20n3.pdf>. Acesso em: 02/04/2016. 